\title{
The Development of Mobile Application to Introduce Historical Monuments in Manado
}

\author{
Moshe Markhasi Rupilu ${ }^{1, *}$, Suyoto $^{1}$, and Albertus Joko Santoso ${ }^{1}$ \\ ${ }^{1}$ Magister Informatics Engineering, Universitas Atma Jaya Yogyakarta, Yogyakarta, Indonesia 55281
}

\begin{abstract}
Learning the historical value of a monument is important because it preserves cultural and historical values, as well as expanding our personal insight. In Indonesia, particularly in Manado, North Sulawesi, there are many monuments. The monuments are erected for history, religion, culture and past war, however these aren't written in detail in the monuments. To get information on specific monument, manual search was required, i.e. asking related people or sources. Based on the problem, the development of an application which can utilize LBS (Location Based Service) method and some algorithmic methods specifically designed for mobile devices such as Smartphone, was required so that information on every monument in Manado can be displayed in detail using GPS coord inate. The application was developed by $\mathrm{KNN}$ method with K-means algorithm and collaborative filtering to recommend monument information to tourist. Tourists will get recommended options filtered by distance. Then, this method was also used to look for the closest monument from user. KNN algorithm determines the closest location by making comparisons according to calculation of longitude and latitude of several monuments tourist wants to visit. With this application, tourists who want to know and find information on monuments in Manado can do them easily and quickly because monument information is recommended directly to user without having to make selection. Moreover, tourist can see recommended monument information and search several monuments in Manado in real time.
\end{abstract}

\section{Introduction}

Manado is one of the most famous tourism destination in Indonesia and is located in Asia-Pacific, which is bordering on the Philippines, Republic of Palau and the Pacific Ocean [1]. It is nicknamed Maldives Van Celeb because this city has the beautiful National Park of Bunaken which is similar with Maldives (Maldives) in the north-western tip of Sulawesi [2]. Beside Bunaken, Manado also has many interesting destinations which are historical monuments that have religious history, cultural history, and even the history of Indonesian Independence struggle. Cultural diversity and monuments make Manado as a city that has so many tourism destinations. In fact, in 2017, there is government program which is MWTC (Manado as World Tourism Centre 2017) so that Manado becomes the destination of the International and Local tourists. Travelling is a necessity that cannot be separated from human life. The monuments are needed by tourists in order to experience adventure tour in Manado.

Access to information services are still inadequate and not proportional with many tourism destinations that are available, especially the monuments in Manado. Tourists get difficult to find the locations. They are not getting detailed information's about the destinations they want to visit, for example, they cannot get information about route which is short, safe, and free from congestion. So, the time wasted on the way to the location, even the tourists can have over budget to hire a tour guide who is not organized.
The development of information technology, especially mobile phones, becomes a facility that improves services in accessing the data needed by tourist to know the locations, distance, and description of the monuments in Manado. One result of the mobile technology development is the emergence of a mobile phone that has Android as its operation system. The term "Android" comes from the Greek word with the prefix and that means "male" and the suffix -elides means "the same or similar", the full meaning is together "to be human". Android is a set of software for mobile device that has a relationship between one to another and becomes a set of system programs or a set of application programs that forms a complete system [3].

Android is meant to revolutionize the mobile phone market by bringing internet to mobile phone and enabling its operations just like operating a personal computer (PC), so with Android, consumers can easily get information's via smart applications on their phone [3]. An application that consists of information's about the historical monuments such as location, distance, and their description is needed for accuracy in determining which monuments are priority and can be visited by tourists.

Based on the problems described above, there is an application that can help visitors and tourists in finding information and location of the monument in Manado. The application is location-based service (LBS). LBS means mobile service providers facilitate their mobile phone with information about tourism destination that based on their users location. 


\section{Literature Review}

The development of mobile campus applications to guide students, parents, and/or visitors in finding places on campus. By using LBS (Location Based Service) and NFC (Near Field Communication) feature, phones will be connected automatically in close range with other NFC phones [4]. The increase of popular Smartphone also opens opportunities for mobile services to develop mobile tourism application to suggest tourism destinations based on context factors such as location, weather, and time available. This mobile tourism application is seen as the most efficient way to help travelers on their trip.

Location Based Service (LBS) is a service which is location-based, and will be accessed via mobile device (Smartphone, etc.) So that, it can display a map along with the location where the mobile device is located. Location-based service (LBS) provide customized information according to user characteristics, so it can be easily expanded for many other usages, such as guiding routes for transportation systems or for tourism destination [5].

Location-Based Services application provides a set of services for users who are from geographic location of mobile devices. Use of this service makes it possible for users to search and find other people, vehicles, resources and provide location-sensitive services, besides tracking their own location. Requests for location may come from mobile devices or other entities such as application or networks providers. It is possible to automatically trigger Location Based Services when the mobile device is in a particular location. In this study, it is discussed how to implement location-based services on Android [6].

It is possible to automatically trigger Location Based Service when the mobile device is in a particular Location. This service can also be derived from the user's mobile device to meet location-based requests such as finding areas of interest, checking traffic conditions, finding friends, vehicles, resources, machinery and emergency requests. This study will discuss how to implement location-based services on Android [7].

Developing Location Based Services applications uses data mining for mobile users. Data Mining aims to find interesting and useful knowledge from the database. Conventionally, the data were analyzed manually. Many useful relationships are not revealed and may not be user identity. Through data mining, it can extract interesting knowledge and regularity. Mobile application which is built using Data Mining approach can find the nearest and famous location around a certain area. By using the data mining approach, it extracts the database with the help of different data mining algorithms. The nearest location is determined by the wireless network. It provides data using open source Android. It provides a world-class platform for creating applications and games for android users everywhere, and open markets for immediate distribution to users [8].

Mobile computing has grown in such a way that users can access all the information on a single device where people are always moving with mobile devices like laptops, cell phones, tablets, etc. Using a user geographic location, many of the information's related to mobile device users can be collected. The location information of mobile users can improve the class of services and applications that can be provided to mobile device users. These application and service classes are called as location-based service. Location Based Services (LBS) is a type of service that helps obtaining user's geographic location and more useful information near the user's location. This location-based information can be obtained by various terms such as position, vicinity, proximity, context, maps, routes, places, and more [9].

Design of tour guide system is based on three layers of architecture. The architecture includes the browser layer, top layer and bottom layer. It uses KNN algorithms and collaborative filtering to calculate and recommend tourism information to users. Limitations found in this study are the application is not very efficient in providing information and predicting the right places with an affordable price [10].

Tour guide system uses web technology services and three layers architecture, by using web technology and three layers architecture that are browser layer, business logic layer and server layer. Lucene is used to create an index for data which is used to execute efficient requests. Limitations found in this study are the differences in the number of Geographic description details of the code at different locations, for example, one place has information and detail description in the form of building address, but the other place only has city name and zip code [11].

\section{Research Methodology}

In conducting this research there is a research methodology used to obtain information that is completely understood and the results in accordance with the expected results, as well as get the results of quality scientific work [12]. Therefore, the researcher uses methods in the form of: Methods of data collection uses interviews and field studies. Interviews were conducted with local tourism authorities to obtain information in monuments in Manado. In addition, researcher also uses sources from other existing research such as journals, papers and reference books. Research methods can be described as follows [13].

\subsection{Observation Method}

At this stage, researcher collects data by doing observation to monuments that are interesting.

\subsection{Library Method}

This method is data collection by studying books (literature study), journals and other references that are related to this research.

For developing monument recommendation system, it uses initial determination of $\mathrm{KNN}$ algorithm, 
grouping items with K-means and the process of filtering or evaluating items with collaborative filtering. KNearest Neighbor (KNN) algorithm is a method to classify objects based on learning that is very close to the object. The working principle of K-Nearest Neighbor (KNN) is to find the closest distance between the data that will be evaluated with the nearest K-Neighbor in the training data.

$$
d_{i}=\sqrt{\sum_{i=1}^{p}\left(X_{2 i}-X_{1 i}\right)^{2}}
$$

One of partition algorithm is the K-means algorithm, it is algorithm based on the definition of initial centroid after determining the number of first group. The process is periodically used in the K-means algorithm to obtain a database cluster. The data items in this algorithm are grouped into a data set according to the closest distance to a cluster [14].

Filtering process or evaluating items which are based on the perceptions of other users becomes an important determinant of collaborative filtering algorithm. A profile is used to filter a number of items. Collection and profile development become a collaborative filtering technique, then determine the relationship between the suitability of model equations and data. The purpose of collaborative filtering is to filter number of items which users select, and provide recommendations to users with the remaining options [15].

\section{Analysis}

In developing this system, it is required a phase which is called analysis phase, and there will be need analysis in this phase. This phase is done because the system that is made sometimes is not working as what system maker expects. this problem happens because need analysis is not done correctly. The purpose of the phase is to examine and identify problems that happen to system users, so that systems which will be built and developed in accordance with what is expected by the user. Besides, disadvantages and errors in building the system can be minimized by making or adding minor changes to the built system.

Information about the monuments is the important thing that should be given to tourists, and one of the information that must be covered is the monuments location. There are still many tourists who do not know about the existence of monuments in Manado, they do not know about the location of each monument, address, short description, route location and related information needed. This obstacle happens, because not all tourists know the location and information related to the existing monument, especially for tourists who visit one of the monuments in Manado for the first time.
Tourists still search information manually by asking other people who they meet, besides, some of them find the information from brochures in the form of hardcopy, or find monument information via internet. However, the search for monument information by reading brochure is rarely encountered because of the globalization. Similarly, asking others is also rarely done now, because the information that they get is limited to the experience of person they meet. In addition, searching the information on the internet is not helpful enough because there is no special website that provides sufficient information's about the monuments. Therefore, it is necessary to develop a system that can help and facilitate the tourists to obtain the monument information's that are recommended in a real time.

As the result of this study, the proposed system is developing a system that can recommend the right monument to the users regarding the existence of monuments in Manado. Tourists can be facilitated by the recommendation about the monument they want to visit. The information displayed is recommended monument, brief description, map and route location to the monument using Smartphone device through mobile monument application.

\section{Design}

Design phase is the stage that describes the application design and develops the system structure. This stage includes modelling data, architecture, interface design and the implementation.



Fig. 1. Architecture of Manado Monument

This phase describes about design process that will be transformed into software design, which can be predicted before it is implemented into the program. The process will focus on determining the overall system architecture, the design phase will also be used to perform system-building activities. Then, in developing this system, use-case is used to explain what users can do to monument recommendation system using mobile device. Figure 2 shows the use-case diagram of the monument recommendation system. 


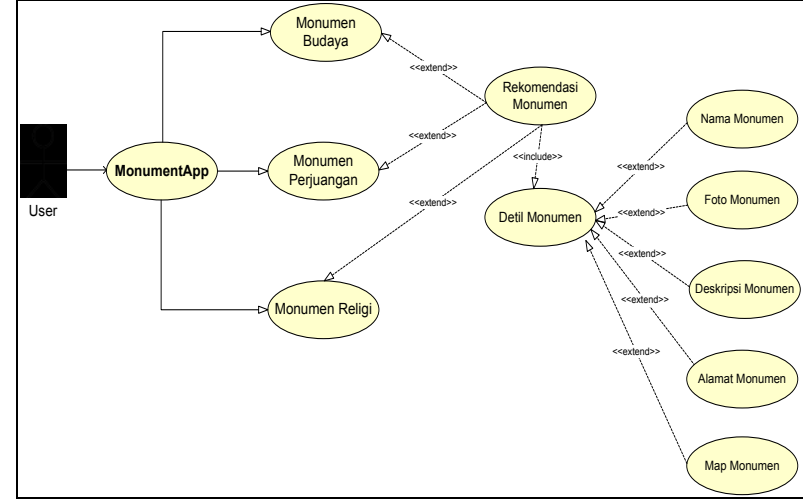

Fig. 2. The Case Monument Recommended

The following is the design of monument recommendation system architecture that will be shown in Figure 3 below.



Fig. 3. Monument System Architecture Design

\section{Results and Discussion}

The monument recommendation system which is built uses four modules in its application. The first module is used for system authentication purposes, the second module is used to display the initial system interface, the third module is used to display monument recommendations to users and the fourth module is used to display details of the monuments.

In module 1, there is checking system about user registration that is done by monument recommendation system. If users have not registered, they can register in the system directly. After done registration, user will get authentication from the system, then they can access the system.

In module 2, system will display the monument categories which are historical, cultural, and religious monuments. The classification of monuments will use different icons in representing them, in order to ease users when they select category they want. Each recommendation of the monument given will be shown with the list of monuments based on the classification. Besides, there are also features to know information about the use of system and how to use it.

Module 3 is used to provide information about classification of the monuments. The information displayed is a list of monuments recommended. Furthermore, in Module 4, each monument classification will display detailed information, maps and location routes that are needed by the users. The maps and routes are displayed on Google Maps that is tracking users' location by utilizing GPS. GPS is a navigation system that gives information about the coordinate of users location. Then, the system will display some interesting locations or other places such as public facilities, cafes, airports and so forth.

Users can interact into the system using Smartphone devices to access GPS using monument applications, but GPS must be active to do it. Then, the system will respond command given by performing related processes. The process will provide the information needed according to the longitude and latitude to display the monument in interface system. In addition, the system also automatically reads the database related to some monuments through the information that has been built, and the monument will be displayed based on each choice according to wishes of the user. Monuments displayed include historical monuments, cultural monuments and religious monuments.

Information's displayed by Manado monument application are:

\subsection{Cultural Monument}

- Kesatuan Bangsa Park

- City Park Monument

- Adipura Monument

- Boboca Monument

- Toar Lumimuut Monument

\subsection{Monuments of Struggle}

- The monument of Worang Battalion Landing

- Monument of World War 2 (Sentrum Church)

- Sam Ratulangi Monument

- Zero Point Monument

- Moraya Castle

\subsection{Religious Monument}

- Statue of Blessing Jesus

- The Tree of Love

- Cross Warembungan Monument

- The Hill of Love

- Coral Triangle Monument

$\mathrm{KNN}$ algorithm is used to find and get the distance between items and users needs in cluster. Then, the classification can be grouped in neighboring categories. $\mathrm{K}$-mean algorithm is used to observe and group items into the allocation of several sections to each cluster observation, according to the nearest mean, as well as the prototype cluster. Collaborative filtering is used to filter the users choice which then recommend some of remaining options to the users.

To calculate the suitability between tourist object criteria and tourists needs, similarity formula is used.

$\operatorname{Similarity}(P, C)=(s 1 * w 1+s 2 * w 2+\ldots+s n * w n) /$ $(w 1+w 2+\ldots+w n)$ 
Information:

P: Problem

C: case

S: similarity which is 1 (similar) 0 (different)

$\mathrm{W}=$ weight (weight given).

\section{Case Study}

Giving weight to tourist priority.

Main Prio rity $=5(w)$

Criteria of tourism destination that become main priority are:

1. Cultural Monument

2. Monument of Struggle

3. Religious monuments

4. Toilet

5. Cheap Price

Medium Prio rity $=3(\mathrm{w})$

The criteria of tourism places which become medium priority are:

1. Restaurant

2. Lodge

3. Medium price

Low priority $=1(\mathrm{w})$

Criteria of tourism place that become low priority are:

1. Souvenir

2. The expensive price

In this case study, there is a new user who will search for tourist attractions with the following criteria:
1. Museum of struggle
2. Medium Price
3. Lodge
4. Restaurant

The system already has the data of previous cases such as in table 1 below.

Table 1. The data of selecting tourist attractions

\begin{tabular}{|l|l|}
\hline Criteria: & \\
1. Cultural Museum & Solution: \\
2. Medium Price & Toar Lumimuut Monument \\
3. Toilet & \\
4. Souvenir & \\
5. Restaurant & \\
\hline Case 2 & \\
Criteria: & \\
1. Museum of & \\
Struggle & Solutions: \\
2. Expensive Price & Sam Ratulagi monument \\
3. Toilet & \\
4. Souvenir & \\
5. Lodges & \\
6. Restaurants & \\
\hline Case 3 & \\
Criteria: & \\
1. Religious Museum & Solution: \\
2. Medium Price & The Hill of Love \\
3. Toilet & \\
4. Restaurant & \\
& \\
\hline
\end{tabular}

In order to make the system recommend users about which place to visit, so calculation and selecting one of the cases that is very close to user criteria need to be done.
Calculation 1 (case 1)

Cultural Museum $=5$

Medium Price $=3$

Toilet $=5$

Souvenirs $=1$

Restaurant $=3$

Similarity

$$
(\mathrm{X}, 1)=(0 * 5+1 * 3+0 * 5+0 * 1+1 * 3) /(5+3+5+1+3)=0.35
$$

Calculation 2 (case 2)

Museum of Struggle $=5$

Expensive Price $=1$

Toilet $=5$

Souvenirs $=1$

Lodge $=3$

Restaurant $=3$

Similarity

$(\mathrm{X}, 1)=$

$(1 * 5+0 * 1+0 * 5+0 * 1+1 * 3+1 * 3) /(5+1+5+1+3+3)=0.64$

Calculation 3 (case 3)

Religious Museum $=5$

Medium Price $=3$

Toilet $=5$

Restaurant $=3$

Similarity

$(X, 1)=(0 * 5+1 * 3+0 * 5+1 * 3) /(5+3+5+3)=0.37$

From three cases that have occurred. The case that has a value close to 1 is case number 2 . The solution in case 2 can be used as a recommendation to the new user.

The initial interface implementation is displayed when the user selects the monument icon. It can be shown in the following picture.

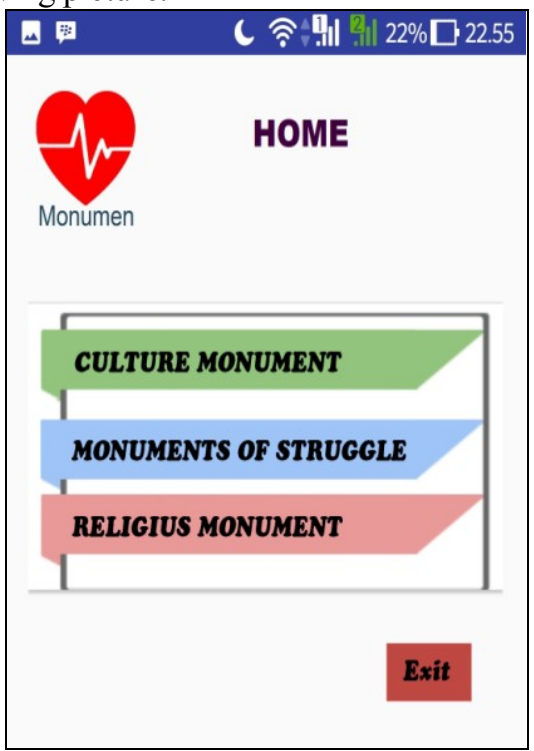

Fig. 4. Main Interface of Manado Monument

In the interface picture above, it shows the initial interface of monument recommendation system that consists of historical monuments, cultural monuments, and religious monuments. Each monument has been distinguished according to its category and lists. The lists are list of historical monuments, list of cultural monuments, and list of religious monuments. Through 
the monument lists, users can find detailed monument information or can find map of monument locations and monument location routes that can direct users to the monument they want to go.

Then, maps and routes to the monuments which are recommended by the system, will be shown in the following picture.

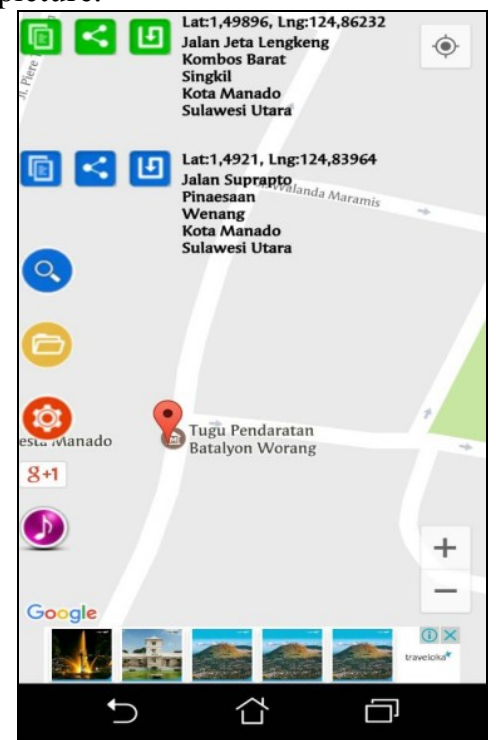

Fig. 5. Map and Monument Route Interface

The picture above shows map of the location and route of one monument that has been recommended by the system when the user selects the monument as he wishes. The system will respond and give route of the location to the monument based on the user starting position by using GPS support on the user's mobile device.

\section{Conclusions}

In this research, researcher presents a design for the monument recommendation system using mobile devices' location-based services (LBS), KNN, K-Nearst, and Collaborating Filtering. The monument recommendation system makes tourists get information about the monument in Manado more easily and efficiently. Monument location can be obtained using the directions menu on each monument that aims to facilitate the users in order to reach the location, because it displays the route that must be passed from users starting position. The combination of mobile applications using Location Based Services (LBS) and KNN is chosen because it is interactive. It means that there is a two-way interaction between users and the system, which the system will easily recommend interesting monuments that can be selected by tourists. So, tourists realize that monuments' attractiveness in Manado increases.

\section{References}

1. A. E. Tungka, A. A. Omran, A. O. Gebril, W. S. Wah, And A. B. Suprapti, "Manado Waterfront Development Concept As Sustainable City Of Tourism," ACTA Tech. CORVINIENSIS - Bull. Eng., pp. 31-36, 2012.

2. Kholil and D. Tangian, Int. J. Dev. Sustain., vol. 1, no. 2, pp. 391-401, 2012.

3. O. Uke and A. Shaikh, Int. J. Comput. Appl., vol. 2, no. 2, pp. 543-549, 2016.

4. S. Bhattacharya and M. B. Panbu, Int. J. Innov. Technol. Explor. Eng., vol. 2, no. 3, pp. 25-29, 2013.

5. J. M. Noguera, M. J. Barranco, R. J. Segura, and L. Martínez, "A Mobile 3D-GIS Hybrid Recommender System For Tourism,” pp. 37-52, 2012.

6. J. M. Noguera, M. J. Barranco, R. J. Segura, and L. Martínez, Inf. Sci. (Ny)., vol. 215, pp. 37-52, 2012.

7. C. R. Rani, A. P. Kumar, D. Adarsh, K. K. Mohan, and K.V.Kiran, Int. J. Adv. Eng. Technol., vol. 3, no. 1, pp. 209-220, 2012.

8. A. Malik and M. A. Kajala, Int. J. Recent Innov. Trends Comput. Commun., vol. 2, no. 4, pp. 920923, 2014.

9. P. Doshi, P. Jain, and A. Shakwala, Int. J. Eng. Comput. Sci., vol. 3, no. 3, pp. 5072-5077, 2014.

10. Mrs.S.S.Pawar, M. A. S.Kadam, M. P. R. Chavhan, M. P. R. Ranjane, and M. A. S. Lohar, Int. J. Eng. Technol. Manag. Appl. Sci., vol. 4, no. 2, pp. 4246, 2016.

11. B. S. N. Reddy and D. R. P. Sam, Int. J. Comput. Trends Technol., vol. 4, no. 5, pp. 1287-1290, 2013.

12. V. S. Molchanova, Eur. J. Soc. Hum. Sci., vol. 2, no. 2, pp. 75-80, 2014.

13. P. P. A. Manjare, M. P. V. Ninawe, M. M. L. Dabhire, M. R. S. Bonde, M. D. S. Charhate, and M. M. S. Gawande, Int. Res. J. Eng. Technol., vol. 3, no. 4, pp. 877-881, 2016.

14. U. R. Raval and C. Jani, Int. J. Comput. Sci. Mob. Comput., vol. 4, no. 11, pp. 72-76, 2015.

15. M. A. Hameed, O. Al Jadaan, and S. Ramachandram, Int. J. Comput. Sci. Eng., vol. 4, no. 5, pp. 859-876, 2012. 